Langdon, P.E. \& Talbot, T.J. (2006). Locus of control and sex offenders with an intellectual disability. The International Journal of Offender Therapy and Comparative Criminology, 50, 391-401.

\title{
Locus of Control and Sex Offenders with an Intellectual Disability
}

\author{
Peter E Langdon* BSc(Hons), PGCertHE., DClinPsy, AFBPsS, CPsychol. \\ School of Medicine, Health Policy and Practice, University of East Anglia, \\ Norwich, United Kingdom, NR4 7TJ \\ $\&$ \\ Broadland Clinic Forensic Service, Norfolk Learning Difficulties Service, \\ Norwich Primary Care NHS Trust \\ Norwich, United Kingdom, NR13 5EW \\ Tiffany J Talbot BSc(Hons), ClinPsyD \\ School of Medicine, Health Policy and Practice, University of East Anglia \\ Norwich, United Kingdom, NR4 7TJ
}

*Requests for reprints should be addressed to : Dr Peter E Langdon, Lecturer in Clinical Psychology, School of Medicine, Health Policy and Practice, University of East Anglia, NR4 7TJ, United Kingdom Telephone: +44 01603593599 Fax: +44 1603593604 Email P.Langdon@uea.ac.uk WWW:

http://www.med.uea.ac.uk/psychology 


\begin{abstract}
Locus of control has been implicated as an important construct that is related to treatment outcome for several groups of offenders, including sexual offenders. However, little attention has been paid to how this construct is related to sexual offending by people with intellectual disabilities. Given this, forty-one participants with intellectual disabilities were recruited into three groups, 1) sex offenders who had undergone psychological treatment, 2) sex offenders who had no history of treatment, and 3) non-offenders. All participants completed a measure of locus of control and a measure of distorted cognitions. There was a significant difference between those who had and had not completed treatment in terms of cognitive distortions relating to sexual offending. There was no significant difference between the three groups on the measure of locus of control, with all three groups endorsing an external locus of control. Three possible explanations for how locus of control relates to sexual offending by people with intellectual disabilities is explored and discussed in light of the results.
\end{abstract}

KEYWORDS: Locus of Control, Intellectual Disability, Learning Disability, Sex Offender, Sex Offence, Dynamic Risk Factors, Distorted Cognitions, QACSO 


\section{Background}

Locus of control (Rotter, 1966) is a construct that has been construed along the dimensions of external and internal. Lefcourt (1976) described an internal locus of control as the "perceptions of events, whether positive or negative, as being a consequence of one's own actions and thereby potentially under personal control", while an external locus of control was defined as the, "perception of positive or negative events as being unrelated to one's own behavior and thereby beyond personal control".

This construct is of particular interest to clinicians providing treatments in forensic settings as it has been linked to treatment outcomes for sex offenders (Fisher, Beech, \& Browne, 1998), and drug users (Dekel, Benbenishty \& Amram, 2004), and has been hypothesised to be related to Prochaska and DiClemente's (1983) Transtheoretical Model of Change in a study that used court-referred and self-referred domestic violence offenders (Bowen \& Gilchrist, 2004). Others have suggested that locus of control may act as a reliable indicator of treatment amenability in young offenders (Page \& Scalora, 2004)

In fact, Page and Scalora (2004) reviewed the literature pertaining to locus of control and its relationship to treatment participation, help-seeking, and treatment outcomes amongst young offenders. They suggest that a shift from an external to 
an internal locus of control as a result of treatment may reflect a positive treatment impact, while no shift, a shift from the internal to the external, or an increase in magnitude of external locus of control, may indicate ineffective treatment. They also suggest that an assessment of locus of control prior to intervention may provide some indication of how amenable a person may be to treatment.

Considering people with an intellectual disability, there are a variety of studies which report that people with intellectual disabilities generally endorse an external locus of control (Gardner, Warren \& Gardner, 1977; Koscielak, 1988; Riedel \& Milgram, 1970; Wehmeyer, 1994; Wehmeyer \& Palmer, 1997). However, Mamlin, Harris \& Case (2001) in a review of studies investigating locus of control amongst students with intellectual disabilities have cast some doubt on this conclusion, although there are some differences between the United States and Great Britain in terms of the definition of an intellectual disability. Nevertheless, the conclusion that people with intellectual disabilities generally endorse an external locus of control raises interesting questions about the utility of this construct for predicting treatment amenability or outcome with this population. 
There are no known studies which have examined locus of control and how it relates to treatment outcome amongst people with intellectual disabilities, including sex offenders. However, Rose, Jenkins, O’Connor, Jones \& Felce (2002), in a small case study series investigating the effectiveness of cognitive behavioral treatment for men with intellectual disabilities with a history of sexual offending demonstrated that locus of control actually became more external as a result of treatment. They suggested that this may have arisen as a consequence of the treatment itself, which may have emphasized the external consequences of sexual offending behavior. Considering the hypothesized relationship between locus of control and treatment outcome suggested by Page \& Scalora (2004), if applied without modification to the Rose et al., (2002) study, would lead to the conclusion that treatment was ineffectual.

No other known studies have examined locus of control amongst sex offenders with intellectual disabilities. However, this construct has been indicated as an important variable in predicting treatment outcome amongst sex offenders without an intellectual disability. Fisher et al., (1998) reported that sex offenders who had successfully completed treatment compared to sex offenders who had unsuccessfully completed treatment differed in terms of locus of control, with successful completion of treatment being associated with an internal locus of control at pre-and post-treatment. They also noted a relationship between 
intelligence measures and locus of control, in that those with a lower IQ score were more likely to endorse an external locus of control. Beech \& Fisher (2002) have gone on to describe a model of treatment for sex offenders where locus of control is hypothesized to act as a mediator of treatment effectiveness.

This literature raises interesting questions for how locus of control is related to treatment outcome for sex offenders with an intellectual disability. Locus of control would appear to be an important factor that affects treatment outcome for several groups, including sex offenders (Fisher et al., 1998), drug users (Dekel et al., 2004), and adolescent offenders (Page \& Scalora, 2004). People with intellectual disabilities appear to generally endorse an external locus of control (Gardner, Warren \& Gardner, 1977; Koscielak, 1988; Riedel \& Milgram, 1970; Wehmeyer, 1994; Wehmeyer \& Palmer, 1997), and this subsequently raises questions about how locus of control is related to treatment outcome for offenders with intellectual disabilities.

Given these findings, the current small study was undertaken to initially explore locus of control amongst three groups, 1) men with intellectual disabilities who have committed sexual offences and undergone treatment, 2) men with intellectual disabilities who have committed sexual offences and are yet to receive treatment, and 3) a group of men with intellectual disabilities and who are not sex 
offenders. If locus of control is related to treatment outcome for people with intellectual disabilities, in a similar way to people without intellectual disabilities, we would expect significant differences between the three groups included in the study. Specifically, sex offenders who had undergone treatment and people who are not sex offenders should report more of an internal locus of control while sex offenders who are yet to receive treatment should report more of an external locus of control. In addition to this, we also administered a measure of distorted cognitions to all of our participants. It was hypothesized that sex offenders who had undergone psychological treatment and participants who were not sex offenders would endorse significantly fewer cognitive distortions than sex offenders who had not undergone treatment, suggesting that previous psychological interventions may have been effective in reducing levels of distorted thinking.

\section{Method}

\section{Participants}

The current study made use of forty-one participants spread across three groups:

1) twelve men with an intellectual disability who had a history of sexual

offending behavior and some history of engagement in psychological interventions aimed at addressing their offending behavior (Treatment Group), 2) eleven men with an intellectual disability who had a history of sexual offending 
behavior and had not received any psychological treatment (No Treatment Group), and 3) eighteen men with an intellectual disability and no known history of sexually inappropriate behavior (Non-Offenders)

Participants with an intellectual disability who had a history of sexual offending behavior and engagement in treatment $(M$ Age $=32.18, \mathrm{SD}=10.73 ; M$ WAIS-III Full Scale IQ=65.92; $\mathrm{SD}=8.75$ ), along with participants who had a history of sexual offending and no history of treatment $(M$ Age=35.62, $\mathrm{SD}=13.54 ; M$ WAIS-III Full Scale IQ=64.57; SD=4.61), were recruited from secure intellectual disabilities services within the East Anglia region of the United Kingdom. There were no significant differences between the two groups in terms of their offending histories (Table 1). Twelve of these participants had taken part in a Sex Offender Treatment Group previously, while the remaining eleven men were yet to receive any psychological treatment. Those who had participated previously in treatment had received group based cognitive behavioral treatment of some form. However, there were differences between the treatment that had been offered across different services and localities, and the current study did not aim to evaluate these interventions. As such, only limited information was available with respect to treatment. A measure of distorted cognitions was administered to participants in order to generate some evidence as to whether or not previous treatment had 
been successful at modifying offender's endorsement of cognitive distortions related to sexual offending.

Participants with an intellectual disability who did not have a history of sexually inappropriate behavior $(M$ Age=28.83; $\mathrm{SD}=6.09$; $M$ WAIS-III Full Scale $\mathrm{IQ}=62.4 ; \mathrm{SD}=6.44)$ were recruited from residential units within the East Anglia region of the United Kingdom.

There were no significant difference between the three groups in terms their level of general intellectual functioning $(\mathrm{F}(2,38)=<1)$ and age $(\mathrm{F}(2,38)=1.75 ; \mathrm{p}=0.19)$.

\section{Design and Procedure}

A between-subjects design was employed to allow comparisons across the three independent groups outlined above. All participants completed the Questionnaire on Attitudes Consistent with Sexual Offending (QACSO; Broxholme \& Lindsay, 2003) and the Adult Nowicki-Strickland Internal-External Scale (Nowicki \& Duke, 1974).

The QACSO is a 63 item questionnaire specifically designed for use with sex offenders who have intellectual disabilities. The questionnaire attempts to assess distorted cognitions relating to sexual offending spread across several different 
offending categories, which include 1) rape, 2) voyeurism, 3) exhibitionism, 4) dating abuse, 5) homosexual assault, 6) pedophilia, and 7) stalking and sexual harassment. The QACSO has been found to effectively discriminate between sex offenders and non-offenders with an intellectual disability, and generally good levels of test-retest reliability for all of the offending categories, with the exception of the rape category, have been reported (Broxholme \& Lindsay, 2003).

The Adult Nowicki-Strickland Internal-External Scale was designed to quantify the extent to which a person believes that events occur either as a result of their own behavior (internal locus of control) or as a consequence of events out of their control, such as luck, fate or others (external locus of control). The NowickiStrickland measure of locus of control was chosen for the current study as this is one of the most widely used measures of locus of control and has been previously used with adults with intellectual disabilities (Wehmeyer, 1994; Wehmeyer \& Palmer, 1997) including adults with intellectual disabilities who have a history of sexual offending (Rose et al., 2002), along with sex offenders without an intellectual disability (Fisher et al., 1998).

The Nowicki-Strickland Internal-External Scale has forty items requiring a 'yes' or 'no' response and test-retest reliability has been reported to be $\mathrm{r}=0.83$ (Nowicki \& Duke, 1974). Fisher et al., (1998) have derived cut-off scores for this measure 
where scores of eleven or less represent the endorsement of an internal locus of control, while scores of twelve or greater represent an external locus of control.

Appointments were arranged with all participants where appropriate consent to participate in research was gained directly from the participant. Where consent was obtained, the participant completed the questionnaires which took approximately forty minutes. Questionnaire items were read aloud to each participant and their answers recorded. This was done to account for the possibility that many of the participants may have had difficulty reading the questionnaires.

\section{Statistical Analysis}

A one-way Analysis of Variance (ANOVA) and post-hoc tests using the least significant difference method were completed to examine mean differences between the three groups of participants.

\section{Ethics}

The current study received a favorable ethical opinion from the Norfolk Local Research Ethics Committee in the United Kingdom. All of the participants included were judged to have capacity to provide consent to participate in this study. 


\section{Results \& Discussion}

\section{Cognitive Distortions}

There were significant differences between the groups on some sections of the QACSO; these included the Rape $(\mathrm{F}(2,38)=11.34, \mathrm{p}=0.001)$, Exhibitionism $(\mathrm{F}(2$, $38)=3.45, \mathrm{p}=0.042)$, Homosexual Assault $(\mathrm{F}(2,38)=5.40, \mathrm{p}=0.009)$, Pedophilia $(\mathrm{F}(2,38)=5.18, \mathrm{p}=0.01)$, and Stalking and Sexual Harassment $(\mathrm{F}(2,38)=11.25$, $\mathrm{p}=0.000$ ) sections (Table 2 ). There was no significant difference between the groups for the remaining sections. There was also a significant difference between the groups on the total score of the QACSO $(F(2,28)=8.40, \mathrm{p}=0.001$; Table 2$)$.

Post-hoc comparisons revealed that the No Treatment Group scored significantly $(\mathrm{p}<0.05)$ higher than the Treatment Group and the Non-Offender Group on the Rape, Exhibitionism, Homosexual Assault, Pedophilia, Stalking and Sexual Harassment sections of the QACSO, including the total score for the QACSO. There was no significant difference $(\mathrm{p}>0.05)$ between the Treatment Group and the Non-Offender Group on any of the sections of the QACSO, or the total score

of the QACSO. Taken together, these results suggest that previous psychological treatments may have been effective at reducing levels of distorted cognitions amongst sex offenders with an intellectual disability.

\section{Locus of Control}


The mean scores for each of the three groups on the Adult Nowicki-Strickland Internal-External Scale suggested that participants endorsed an external locus of control, according to the cut-off scores recommended by Fisher et al., (1998;

Table 3). There was no significant difference between the three groups $(\mathrm{F}(2,50)=$ $<1)$. Given this, post hoc tests were not completed.

Comparing the current means scores across the three groups to previous studies that used the same measure revealed a good degree of consistency between studies. For example, Wehmeyer (1994) reported a mean score for adults with intellectual disabilities of $18.5(\mathrm{SD}=4.3)$.

\section{Implications}

The current results have some interesting implications for our understanding of treatment outcome for sex offenders who have intellectual disabilities. Within the current study, previous psychological treatment appears to have successfully augmented the number of distorted cognitions endorsed by sex offenders with an intellectual disability, while there was no difference between the three groups with respect to locus of control. Previous studies implicate locus of control as an important factor which affects treatment outcome for sex offenders without an intellectual disability where an external locus of control is associated with poorer treatment outcome (Fisher et al., 1998). Page \& Scalora (2004) argued that locus 
of control is likely to be a good predictor of treatment amenability and outcome amongst young offenders and drew similar conclusions to Fisher et al., (1998). Given the suggestions of these authors, it would make sense to suggest that, within the current study, levels of distorted cognitions should not have differed significantly between sex offenders who had and had not undergone treatment, given that both these groups endorsed an external locus of control.

However, the current results, and previous studies (Gardner, Warren \& Gardner, 1977; Koscielak, 1988; Riedel \& Milgram, 1970; Wehmeyer, 1994; Wehmeyer \& Palmer, 1997) suggest that people with intellectual disabilities, including those who are sex offenders (Rose et al., 2002) may endorse an external locus of control regardless, and this raises some interesting questions for how locus of control is related to treatment outcome for people with intellectual disabilities.

There are several possible explanations as to how locus of control may relate to treatment outcome for sex offenders with an intellectual disability. Firstly, it may be the case that locus of control relates to treatment amenability and outcome for sex offenders with an intellectual disability in a similar way to offenders without an intellectual disability. If this were proved to be the case, then sex offenders with an intellectual disability would be expected to have poor outcomes as a result of treatment given the endorsement of an external locus of control. However, this 
conclusion would be problematic in that it would suggest that treatment for sex offenders with intellectual disabilities is likely to be ineffective and there is emerging evidence to the contrary, although these authors have not measured locus of control through-out their intervention (Lindsay \& Smith, 1998; Lindsay et al., 2002; Murphy et al., 2004). Further to this point, if locus of control mediates treatment effectiveness for people within intellectual disabilities who are sex offenders, than it is not entirely clear why levels of distorted cognitions differed between the Treatment and No Treatment Group within the current study; surely treatment effectiveness should have been reduced given that all of the participants endorsed an external locus of control.

Secondly, the failure to find a significant difference between the three groups included in the current study, with respect to locus of control, may have occurred because of difficulties surrounding the measurement of locus of control amongst a population of people with intellectual disabilities. There are two further possibilities associated with this suggestion. Firstly, the Nowicki Strickland Internal External Locus of Control Scale may be an inappropriate measure for use with people with intellectual disabilities and hence is an invalid measure of locus of control for this population. However, this is unlikely as the measure has been validated for use with this population (Wehmeyer, 1994; Wehmeyer \& Palmer, 1997). Secondly, there may be issues associated with the sensitivity of the 
measure for detecting change within a population of people with intellectual disabilities. Given the marked evidence suggesting that people with intellectual disabilities endorse an external locus of control (Gardner, Warren \& Gardner, 1977; Koscielak, 1988; Riedel \& Milgram, 1970; Wehmeyer, 1994; Wehmeyer \& Palmer, 1997), it may be the case that changes in locus of control occur as a result of treatment but the Nowicki-Strickland Internal External Locus of Control Scale is not sensitive enough to detect these changes. This would again suggest that the instrument is not entirely valid for use with people with intellectual disabilities.

Thirdly, it may be the case that locus of control has no relationship or a limited relationship to treatment amenability or outcome for people with an intellectual disability. Several researchers have linked locus of control with theories regarding self-determination amongst people with intellectual disabilities. This includes the work of Powers et al., (1996a, b) who have linked concepts such as locus of control, perceived competence, and self esteem to self-determination. Wehmeyer and colleagues $(1997 ; 1998 ; 2001)$ have also developed a theory of self-determination where self-determination is viewed as the ability to make decisions and choices without excessive external influence or pressure and there is emerging evidence that self-determination is affected by environmental factors such as type of residence (Tossebro, 1995; Wehmeyer, Kelchner \& Richards, 1995). 
Given the theories and findings of previous researchers, self-determination is an important issue for people with intellectual disabilities which is related to locus of control. It would appear that people with intellectual disabilities may be more likely to experience difficulties with self-determination and related constructs such as locus of control, perceived competence, self-esteem and choice. Given these difficulties for the population, locus of control may not act to differentiate sex offenders with intellectual disabilities in the same way as sex offenders without an intellectual disability. Hence, the hypothesized mediating role locus of control plays for sex offenders without an intellectual disability may not exist for sex offenders with an intellectual disability as this is an issue for the entire population of people with intellectual disabilities. In other words, most people with intellectual disabilities endorse an external locus of control, and it is not possible to differentiate groups on the basis of this measure, and hence its relationship to treatment outcome is reduced or limited.

The current study does suggest that the utility of locus of control as a mediator of treatment outcome for sex offenders with an intellectual disability may be questioned. This may be due to a decreased variability in locus of control scores amongst the population of people with intellectual disabilities. As such, other measures of dynamic variables (e.g. victim empathy, distorted cognitions) may 
link more explicitly with treatment outcome amongst sex offenders with intellectual disabilities.

However, the current study is limited in several ways. We have merely demonstrated that there is no significant difference between independent groups, namely sex offenders with intellectual disabilities who have and have not undergone treatment and non-offenders. Our results further suggest that treatment may have had some beneficial effects by reducing the number of distorted cognitions endorsed by sex offenders. However, there are differences between the treatments that were offered to participants which varied across different services. This is a significant flaw to the study, as the researchers had no control over the treatment offered. However, what was known is that the treatment given was group-based and adapted from existing cognitive-behavioral sex offender treatment programs intended for sex offenders without an intellectual disability.

The comparative nature of the current study raises more questions than answers, one of which is how useful locus of control is as a construct for predicting treatment outcome amongst sex offenders with an intellectual disability. The current study did not include a sample of offenders with intellectual disabilities where locus of control was measured pre and post treatment and such a study is 
Locus of Control

required to further unravel any mediating role locus of control has upon treatment outcome for offenders with an intellectual disability. 


\section{References}

Bowen, E. \& Gilchrist, E. (2004). Do court-referred and self-referral domestic violence offenders share the same characteristics? A preliminary comparison of motivation to change, locus of control and anger. Legal and Criminological Psychology, 9, 279-294.

Broxholme, S.L. \& Lindsay, W.R. (2003). Development and preliminary evaluation of a questionnaire on cognitions related to sex offending for use with individuals who have mild intellectual disabilities. Journal of Intellectual Disability Research, 47(6), 472-482.

Dekel, R., Benbenishty, R. \& Amram, Y. (2004). Therapeutic communities for drug addicts: Prediction of long term outcomes. Addictive Behaviors, 1883-1837.

Fisher, D., Beech, A. \& Browne, K. (1998). Locus of control and its relationship to treatment change and abuse history in child sexual abusers. Legal and Criminological Psychology, 3, 1-12.

Gardner, D.C., Warren, S.A. \& Gardner, P.L. (1977). Locus of control and law knowledge: A comparison of normal, retarded and learning disabled adolescents. Adolescence, 12, 103-109.

Koscielak, R. (1988). Locus of control and self-esteem in mildly retarded adolescents. Polish Psychological Bulletin, 19, 145-154.

Lefcourt, H.M. (1976). Locus of Control: Current Trends in Theory and Research. New Jersey: Lawrence Erlbaum Associates.

Lindsay, W.R., Smith, A.H.W. (1998). Responses to treatment for sex offenders with intellectual disability: A comparison of men with 1-2-year probation sentences. Journal of Intellectual Disability Research, 42, 346-353.

Lindsay, W.R., Smith, A.H.W., Law, J., Quinn, K., Anderson, A., Smith, A., Overend, T. \& Allam, R. (2002). A treatment service for sex offenders and abusers with intellectual disability: Characteristics or referrals and evaluation. Journal of Applied Research in Intellectual Disabilities, 15, 166-174.

Murphy, G., Sinclair, N., Hays, S., Offord, G., Langdon, P., Scott, J., Williams, J., Stagg, J., Tufnell., Lippold, T., Mercer, K \& Langhiet, G. (2004). Group cognitive 
behavioural treatment for men with intellectual disabilities at risk of sexual offending. Journal of Intellectual Disability Research, 48, 467.

Nowicki, S. \& Duke, M.P. (1974). A locus of control scale for noncollege as well as college adults. Journal of Personality Assessment, 38, 136-137.

Page, G.L. \& Scalora, M.L. (2004). The utility of locus of control for assessing juvenile amenability to treatment. Aggression and Violent Behavior, 9, 523-534.

Powers L., Sowers J., Turner, A., Nesbitt, M., Knowles, E. \& Ellison, R. (1996a). Take Charge: A model for promoting self-determination among adolescents with challenges. In: Promoting Self-Competence in Child and Youth with Disabilities (eds. L.E. Powers, G.H.S. Singer \& J. Sowers), pp. 291-322. Paul H Brookes, Baltimore, MD.

Powers, L., Wilson, R., Matuszewskit, J., Phillips, A., resin, C., Schumacher, D. \& Gensert, J. (1996b). Tacilitating adolescent self-determination: What does it take? In: Self Determination Across the Life Span: Independence and Choice for People with Disabilities (eds. D.J. Sands \& M. L. Wehmeyer), pp257-284. Paul H Brookes, Baltimore, MD.

Prochaska, J.O. \& DiClimente, C.C. (1983). Stages and processes of self-change of smoking: Toward and integrative model of change. Journal of Consulting and Clinical Psychology, 51, 390-395.

Riedel, W.W. \& Milgram, N.A. (1970). Level of aspiration, locus of control and achievement in retardates and normal children. Psychological Reports, 27, 551557.

Rose, J., Jenkins, R., O’Connor, C., Jones, C. \& Felce, D. (2002). A group treatment for men with intellectual disabilities who sexually offend or abuse. Journal of Applied Research in Intellectual Disabilities, 15, 138-150.

Rotter, J.B. (1966). Generalized expectancies for internal versus external control of reinforcement. Psychological Monograhs, 80, 1-28.

Tossebro, J. (1995). Impact of size revisited: relation of number of residents to self-determination and deprivation. American Journal on Mental retardation, $100,59-67$. 
Wehmeyer, M.L. (1994). Perceptions of self-determination and psychological empowerment of adolescents with mental retardation. Education and Training in Mental Retardation \& Developmental Disabilities, 29, 9-21.

Wehmeyer, M.L. (1997). Self-determination and educational outcome: a definitional framework and implications for intervention. Journal of Developmental and Physical Disabilities, 9, 175-209.

Wehmeyer, M.L. (1998). Self-determination and individuals with significant disabilities: examining meanings and misinterpretations. Journal of the Association for Persons with Severe Handicaps, 23, 5-16.

Wehmeyer, M.L., Kelchner, K. \& Richards, S. (1995). Individual and environmental factors related to the self-determination of adults with mental retardation. Journal of Vocational Rehabiliation, 5, 291-305.

Wehmeyer, M.L. \& Palmer, S.B. (1997). Perceptions of control of students with and without cognitive disabilities. Psychological Reports, 81, 195-206.

Wehmeyer, M.L. (2001). Self-determination and mental retardation. International Review of Research in Mental Retardation, 24, 1-48. 
Table 1: Mean number of sexual offences for sex offenders who had and had not undergone treatment.

\begin{tabular}{|c|c|c|c|c|c|}
\hline & \multicolumn{2}{|c|}{$\begin{array}{c}\text { Treatment } \\
\text { Group } \\
(\mathbf{N}=12)\end{array}$} & \multicolumn{2}{|c|}{$\begin{array}{c}\text { No } \\
\text { Treatment } \\
\text { Group } \\
(\mathbf{N}=\mathbf{1 1})\end{array}$} & \multirow[b]{2}{*}{$t(21)=$} \\
\hline & $M=$ & $\mathrm{SD}=$ & $M=$ & $\mathrm{SD}=$ & \\
\hline $\begin{array}{l}\text { Number of Sexual Offences } \\
\text { Against Male Adults with an } \\
\text { Intellectual Disability }\end{array}$ & 0.17 & 0.39 & 0 & 0 & - \\
\hline $\begin{array}{l}\text { Number of Sexual Offences } \\
\text { Against Female Adults with an } \\
\text { Intellectual Disability }\end{array}$ & 0.17 & 0.39 & 0.29 & 0.76 & $\begin{array}{c}1.48 \\
(\mathrm{p}=0.17)\end{array}$ \\
\hline $\begin{array}{l}\text { Number of Sexual Offences } \\
\text { Against Female Adults }\end{array}$ & 1.67 & 2.38 & 5.42 & 13.93 & $<1$ \\
\hline $\begin{array}{l}\text { Number of Sexual Offences } \\
\text { Against Male Adults }\end{array}$ & 0.33 & 0.78 & 0 & 0 & - \\
\hline $\begin{array}{l}\text { Total Number of Sexual Offences } \\
\text { Against Adults }\end{array}$ & 2.08 & 2.64 & 5.71 & 13.84 & $<1$ \\
\hline $\begin{array}{l}\text { Number of Sexual Offences } \\
\text { Against Female Children }\end{array}$ & 1.67 & 1.30 & 1.86 & 1.07 & $<1$ \\
\hline $\begin{array}{l}\text { Number of Sexual Offences } \\
\text { Against Male Children }\end{array}$ & 0.58 & 0.90 & 0.29 & 0.49 & $<1$ \\
\hline $\begin{array}{l}\text { Total Number of Sexual Offences } \\
\text { Against Children }\end{array}$ & 2.25 & 1.42 & 2.14 & 0.90 & $<1$ \\
\hline $\begin{array}{l}\text { Total Number of Non-Sexual } \\
\text { Offences }\end{array}$ & 0.55 & 1.04 & 1.71 & 1.50 & $\begin{array}{c}1.81 \\
(\mathrm{p}=0.10)\end{array}$ \\
\hline
\end{tabular}


Table 2: Means and Standard Deviations of the three groups on the Questionnaire on Attitudes Consistent with Sex Offending (QACSO).

\begin{tabular}{|c|c|c|c|c|c|c|c|}
\hline & \multicolumn{2}{|c|}{$\begin{array}{c}\text { Treatment } \\
\text { Group }(N=12)\end{array}$} & \multicolumn{2}{|c|}{$\begin{array}{l}\text { No Treatment } \\
\text { Group } \\
(\mathrm{N}=11)\end{array}$} & \multicolumn{2}{|c|}{$\begin{array}{l}\text { Non- } \\
\text { Offenders } \\
(\mathbf{N}=18)\end{array}$} & \multirow[b]{2}{*}{$F(2,38)=$} \\
\hline & $M=$ & $\mathrm{SD}=$ & $M=$ & $\mathbf{S D}=$ & $M=$ & $\mathbf{S D}=$ & \\
\hline Rape & 2.33 & 3.51 & 7.37 & 4.03 & 2.78 & 2.34 & $11.34 * * *$ \\
\hline Voyeurism & 4.67 & 2.90 & 7.91 & 3.64 & 6.61 & 4.04 & 2.33 \\
\hline Exhibitionism & 2.75 & 3.22 & 5.82 & 3.28 & 3.56 & 2.43 & $3.45^{*}$ \\
\hline Dating Abuse & 3.00 & 3.51 & 6.27 & 5.08 & 3.94 & 3.28 & 2.15 \\
\hline Homosexual Assault & 1.25 & 2.05 & 4.27 & 3.29 & 1.72 & 1.93 & $5.40 * *$ \\
\hline Pedophilia & 3.75 & 3.49 & 8.18 & 6.05 & 3.11 & 3.39 & $5.18 * *$ \\
\hline $\begin{array}{l}\text { Stalking and Sexual } \\
\text { Harassment }\end{array}$ & 3.08 & 2.39 & 9.72 & 4.75 & 3.61 & 3.90 & $11.25 * * *$ \\
\hline Total Score & 27.08 & 16.67 & 54.72 & 19.87 & 32.06 & 16.22 & $8.40^{* * *}$ \\
\hline
\end{tabular}


Table 3: Means and Standard Deviations of the three groups on the NowickiStrickland Internal External Control Scale.

\begin{tabular}{|c|c|c|c|c|c|c|c|}
\hline & \multicolumn{2}{|c|}{$\begin{array}{c}\text { Treatment } \\
\text { Group } \\
(\mathbf{N}=12)\end{array}$} & \multicolumn{2}{|c|}{$\begin{array}{l}\text { No Treatment } \\
\text { Group } \\
(\mathrm{N}=11)\end{array}$} & \multicolumn{2}{|c|}{$\begin{array}{c}\text { Non- } \\
\text { Offenders } \\
(\mathbf{N}=\mathbf{1 8})\end{array}$} & \multirow[b]{2}{*}{$F(2,38)=$} \\
\hline & $M=$ & $\mathrm{SD}=$ & $M=$ & $\mathrm{SD}=$ & $M=$ & $\mathbf{S D}=$ & \\
\hline $\begin{array}{l}\text { Nowicki Strickland Internal- } \\
\text { External Control Scale }\end{array}$ & 18.00 & 3.72 & 18.27 & 3.52 & 19.17 & 4.82 & $<1$ \\
\hline
\end{tabular}

